\title{
El silencio positivo desde el punto de vista de las garantías del administrado. En especial, en cuanto a la posible interrupción del plazo
}

\author{
Inmaculada de la Fuente Cabero \\ Doctora Europea en Derecho
}

\begin{abstract}
Sumario: A. PLANTEAMIENTO. B. LAS LICENCIAS URBANÍSTICAS: NATURALEZA, PROCEDIMIENTO Y REQUISITOS PARA SU SOLICITUD Y SU OTORGAMIENTO POR SILENCIO ADMINISTRATIVO. C. LA INEFICACIA DEL SILENCIO CONTRA LEGEM COMO PRINCIPIO Y REVISIÓN DE OFICIO. D. RÉGIMEN JURÍDICO DEL SILENCIO POSITIVO EN CASOS DE POSIBLES DEFICIENCIAS EN LA SOLICITUD DE LA LICENCIA. E. DETERMINACIÓN DE LA FECHA DE SOLICITUD DE LA LICENCIA A EFECTOS DEL INICIO DEL PLAZO DEL SILENCIO POSITIVO. LA AUTOLIQUIDACIÓN PROVISIONAL DE TASAS POR LA LICENCIA. F. RÉGIMEN JURÍDICO DEL SILENCIO POSITIVO EN CASOS DE EMISIÓN DE INFORMES PRECEPTIVOS EN EL MARCO DEL PROCEDIMIENTO DE OTORGAMIENTO DE UNA LICENCIA. G. CONCLUSIONES.
\end{abstract}

\section{A. PLANTEAMIENTO}

Seguidamente se estudian temas relacionados con la solicitud de licencias urbanísticas y su otorgamiento por silencio.

En primer lugar, se expone la doctrina legal y jurisprudencial en materia de solicitudes de licencias urbanísticas y su otorgamiento por silencio positivo.

En segundo lugar, se estudiará el momento de solicitud de la licencia para poder determinar si se ha producido un silencio positivo.

En tercer lugar, habrá que observar los criterios jurídicos aplicables para resolver la cuestión relativa a las consecuencias, desde el punto de vista del silencio positivo, del hecho de la necesidad de emisión de Informes preceptivos sectoriales a lo largo del período de silencio positivo, es decir de tramitación de la licencia en el debido plazo.

\section{B. LAS LICENCIAS URBANÍSTICAS: NATURALEZA, PROCEDIMIENTO Y REQUISITOS PARA SU SOLICITUD Y SU OTORGAMIENTO POR SILENCIO ADMINISTRATIVO}

Señala la jurisprudencia (así, por ejemplo, la STSJ de La Rioja de 18 de enero de 2001, JUR 2001\99400) que «como establece la mejor doctrina del 
Derecho Administrativo, (...) la licencia urbanística reúne las siguientes características: es una autorización que concede la Administración objetiva, real, reglada, neutral, que debe estar motivada y que posee naturaleza declarativa (como aspecto inescindible de la característica anterior)». Igualmente, la STSJ de Castilla y León (Burgos) de 12 de noviembre de 2003 (RJCA 2004l330) señala que «la licencia no es una prerrogativa discrecional de la Administración; es por el contrario un acto reglado de reconocimiento de un derecho preexistente, pero que a la vez implica la constatación administrativa de que, en efecto, tal derecho es ejercitable».

El procedimiento de solicitudes de licencias se regula de forma bastante completa en el artículo 9 del Reglamento de Servicios de las Corporaciones Locales (RSCL) aprobado por Decreto de 17 de junio de 1955.

Viene a establecer así el citado artículo del RSCL que las solicitudes de licencia deberán acompañarse de un proyecto técnico y que en el caso de que se observen deficiencias subsanables se notificará esta circunstancia al peticionario antes de expirar el plazo para resolver la solicitud de la licencia (que, como veremos, según el artículo 195.5 de la Ley Urbanística de Galicia, es de tres meses) a los efectos de que sean subsanadas en el plazo de quince días, interrumpiéndose desde la notificación de la deficiencia y hasta su subsanación el plazo del cómputo de los tres meses para resolver. Asimismo, se indica que en el caso de ser necesario informe de algún Organismo, deberá remitírsele la documentación técnica a dicho Organismo para que proceda a la evacuación del informe en el plazo de cinco días tras la fecha de registro, de modo que, transcurrido el plazo para resolver la solicitud de la licencia (tres meses) sin haberse remitido el informe a la Corporación, deberá entenderse informada favorablemente la solicitud. Por último, se hace referencia al otorgamiento de la licencia por silencio administrativo si una vez transcurridos los plazos para que la Administración otorgue o deniegue la licencia (con la prórroga, en su caso, del período de subsanación de deficiencias) no se hubiere notificado resolución expresa al respecto.

En la legislación autonómica puede por ejemplo seleccionarse, por todas, la legislación de Galicia. Según el artículo 16.4 del Decreto 28/1999, por el que se aprueba el Reglamento de Disciplina Urbanística para el desarrollo y aplicación de la Ley del Suelo de Galicia, «las licencias se otorgarán al amparo de la normativa vigente en el momento de su concesión por acto expreso o por silencio administrativo» ${ }^{1}$.

\footnotetext{
${ }^{1}$ En los artículos 194 y siguientes de la Ley 9/2002, de 30 de diciembre, de Ordenación Urbanística y Protección del Medio Rural de Galicia se regulan en un sentido semejante, aunque mucho menos detallado en el aspecto procedimental, las licencias urbanísticas y su otorgamiento, señalándose expresamente en el artículo 195.5 que las peticiones de licencia se resolverán en el plazo de tres meses desde la presentación de la solicitud de licencia con la documentación completa en el Registro del Ayuntamiento, de modo que, una vez transcurrido dicho plazo sin haberse comunicado ningún acto, se entenderá otorgada la licencia solicitada por silencio administrativo. Se establece asimismo en el artículo 196.5 que en los supuestos en que el ordenamiento jurídico exija, para la ejecución de cualquier activi-
} 
Se establece en el artículo 42 de la Ley 30/1992 que el plazo para resolver se computará desde la presentación de la solicitud en el Registro correspondiente y que dicho cómputo, siguiendo la inspiración del Derecho Público comunitario, se interrumpirá o suspenderá en determinados casos, entre los que, por lo que a nosotros importa, se encuentran, primero, el de que haya que requerir al interesado para la subsanación de deficiencias y aportación de documentos (se suspende el plazo máximo para resolver desde la notificación del requerimiento hasta su cumplimiento, o, en su defecto, el transcurso del plazo concedido para la subsanación o aportación); y, segundo, el de que deban solicitarse informes preceptivos y determinantes del contenido de la resolución a la misma u otra Administración (se suspende el plazo para resolver, durante un máximo de tres meses, desde la petición del informe - que deberá notificarse en todo caso al interesado- hasta su remisión —que también deberá ser comunicada al interesado-).

Por su parte, el artículo 43 de la Ley 30/1992 contiene la regulación del silencio administrativo en los procedimientos iniciados a solicitud del interesado: cuando haya transcurrido el plazo máximo para resolver sin que se haya notificado resolución expresa al interesado, con carácter general, se entenderá estimada la solicitud, es decir, tendrá el silencio carácter positivo. Ello no obstante, el propio precepto prevé algunas excepciones al supuesto general, entre otros, cuando una norma con rango de Ley o norma comunitaria establezca lo contrario, cuando se ejercite el derecho de petición del artículo 29 de la Constitución, cuando se trate de procedimientos cuya estimación tuviera como consecuencia la transferencia al solicitante o a terceros de facultades relativas al dominio público o al servicio público o, por último, cuando se trate de procedimientos de impugnación de actos y disposiciones. En todos estos casos el silencio tendrá efectos desestimatorios.

La jurisprudencia se ha manifestado respecto de la aplicación del silencio positivo a la solicitud y concesión de licencias urbanísticas, señalando, como hace, por todas, la STSJ de Castilla y León (Burgos) de 12 de noviembre de 2003 (RJCA 2004l330) que «es cierto que las licencias administrativas son susceptibles de adquisición por silencio teniendo en cuenta el artículo 43.2 de la LRJ-PAC 30/1992( RCL 1992, 2512, 2775 y RCL 1993, 246) que establece que se podrán entender estimadas las solicitudes de concesión de licencias y autorizaciones de instalaciones (...). La idea que se quiere dejar clara es la de que la utilidad del silencio positivo no es la de ganar o arrebatar una concesión que la Administración discute por el transcurso de un plazo como si se tratara de una prescripción adquisitiva, sino que, por el contrario, su finalidad

dad, autorización de otra Administración Pública en materia medioambiental o de protección del patrimonio histórico-cultural, la licencia municipal urbanística sólo podrá solicitarse con posterioridad a que haya sido otorgada la referida autorización.

El régimen que acabamos de reproducir, del RSCL y de la Ley 9/2002 de Galicia, se ajusta a la regulación general del procedimiento de los artículos 42 y 43 de la Ley 30/1992, de 26 de noviembre, de Régimen Jurídico de las Administraciones Públicas y del Procedimiento Administrativo Común. 
es que ante la pasividad e indiferencia de la Administración, el solicitante pueda interpretar el silencio como ficción a su favor para poder empezar a ejercitar el derecho que pretendía fuera reconocido. Es decir, el silencio opera en sentido positivo sustituyendo la actividad de la Administración porque la situación es diáfana, clara e indiscutible, de tal manera que sólo la falta de voluntad del órgano, o su irregular funcionamiento, han impedido la concesión de licencia que de otra manera nunca se hubiera denegado².

\section{LA INEFICACIA DEL SILENCIO CONTRA LEGEM COMO PRINCIPIO Y REVISIÓN DE OFICIO}

Es muy numerosa la jurisprudencia, que ha entendido que, para que opere la institución del silencio positivo en relación con el otorgamiento de licencias, se requiere la concurrencia simultánea de dos requisitos: el primero es el transcurso de los plazos legales establecidos para que pueda entenderse adquirida la licencia por silencio; el segundo, que la licencia solicitada esté ajustada al planeamiento y al resto del ordenamiento aplicable (entre otras, STS de 27 de diciembre de 1999; STS de 15 de diciembre de 1999; STSJ del País Vasco de 8 marzo de 2006, JUR 2006\168117; STSJ de Madrid de 21 septiembre de 2004, JUR 2004\298983; STSJ de Canarias de 20 de enero de 2006, JUR 2006\100550; STSJ de Navarra de 10 de septiembre de 2004, JUR 20041305583 o STSJ de Galicia de 19 de febrero de 2003, JUR 266860, referida a un supuesto en el que la licencia estaba condicionada a la obtención de permiso por parte de Patrimonio cultural por razón del entorno en que pretende efectuarse la misma).

Es decir, según la teoría general del silencio desarrollada por esta jurisprudencia del orden contencioso-administrativo, la ineficacia del silencio contra legem puede catalogarse de auténtico principio general del Derecho urbanístico arraigado en nuestra legislación.

Sin embargo, este criterio ha de completarse con una doctrina jurisprudencial más matizada, que tiene en cuenta la nueva redacción del artículo 43 de

\footnotetext{
${ }^{2}$ No hemos hecho referencia en este iter procedimental de la obtención de licencias al artículo 9.7.a) del RSCL, que prevé la necesidad de denunciar la mora ante la Comisión Provincial de Urbanismo, donde estuviere constituida, o en su defecto, a la Comisión Provincial de Servicios técnicos, si transcurrieren los plazos máximos para la resolución de la solicitud de licencia sin que se hubiere notificado resolución expresa al solicitante, con el objeto de que dicha Comisión resuelva por subrogación, y de modo que si esta Comisión tampoco notifica acuerdo expreso al interesado en el plazo de un mes, se entienda otorgada la licencia por silencio positivo. La explicación estriba en que ya no es precisa esa denuncia de la mora, anteriormente también contemplada en la certificación de actos presuntos del artículo 44 de la Ley 30/1992, resultando de aplicación la nueva redacción de la Ley 30/92 (concretamente, el art. 43.5 introducido por Ley 4/1999), según la cual el certificado acreditativo del silencio producido previsto ya no es un requisito para la obtención de la licencia por silencio positivo (STSJ del País Vasco de 4 de febrero de 2005 (JUR 2005197836, remitiéndose a la STS de 16 de abril 2004). Sobre los matices acerca de la incardinación de este artículo en el ordenamiento jurídico general, véase T. QUINTANA, EL silencio administrativo, Valencia 2006, pp. 408 y ss.
} 
la Ley 30/1992 tras la reforma operada por la Ley 4/1999. Tal y como señala la Exposición de Motivos de dicha Ley 4/1999: «(...) esta situación de falta de respuesta de la Administración - siempre indeseable - nunca puede causar perjuicios innecesarios al ciudadano, sino que equilibrando los intereses en presencia, normalmente debe hacer valer el interés de quien ha cumplido correctamente con las obligaciones legalmente impuestas».

La Ley 4/1999 pretende que se analice el silencio administrativo en abstracto, y por ello veda la posibilidad de que la licencia urbanística obtenida por silencio administrativo positivo pueda dejar de ser operativa por la existencia de una resolución posterior denegatoria de la solicitud de la licencia dictada una vez finalizado el plazo máximo legal para resolver, ya que, de ser así, sencillamente estaríamos haciendo una interpretación que derogaría y haría superflua la propia reforma efectuada por Ley 4/1999. Así lo establece expresamente su Exposición de Motivos: «Se trata de regular esta capital institución del procedimiento administrativo de forma equilibrada y razonable, por lo que se suprime la certificación de actos presuntos que, como es sabido, permitía a la Administración, una vez finalizados los plazos para resolver y antes de expedir la certificación o que transcurriera el plazo para expedirla, dictar un acto administrativo expreso aun cuando resultara contrario a los efectos del silencio ya producido. Por todo ello, el silencio administrativo positivo producirá un verdadero acto administrativo eficaz, que la Administración pública sólo podrá revisar de acuerdo con los procedimientos de revisión establecidos en la Ley».

Y, en consonancia con la Exposición de Motivos de la Ley 4/1999, el artículo 43.4.a) de la Ley 30/1992 sólo permite a la Administración resolver confirmando el silencio administrativo positivo; en caso contrario, cuando la Administración se percate que han pasado los plazos y que el ciudadano ha obtenido autorización o cualquier otro derecho por silencio administrativo positivo, debe acudir a los procedimientos de revisión previstos en la Ley, no permitiéndosele dictar resolución expresa contraria al silencio administrativo positivo, pues, según el artículo 43.3 de la misma Ley 30/1992, el procedimiento ya ha finalizado.

Precisamente, vamos a comprobar a continuación cómo esta jurisprudencia viene a afirmar que una vez finalizado el plazo para resolver una solicitud de licencia, cuando el efecto del silencio sea positivo, la Administración competente, en caso de que no haya resuelto expresamente, no podrá invocar que la concesión de la licencia por silencio es contraria al ordenamiento jurídico sino acudiendo a los procedimientos de revisión establecidos en los artículos 102 y siguientes de la Ley 30/92.

En este sentido, es ilustrativa la STSJ de Madrid de 17 de diciembre de 2004 (JUR 2005\50582), que afirma expresamente que revisa su anterior doctrina jurisprudencial, al entender que hay que matizar la afirmación de que silencio no puede llegar a aplicarse contra legem, invocando en este sentido 
seis argumentos a favor de la consideración de que tras la Ley 4/99 la Administración no puede oponerse en el ámbito del silencio positivo a que el particular pueda hacer valer ante la Administración dicho silencio positivo, sin perjuicio de la acción revisora de oficio de la Administración. Reproducimos a continuación estos argumentos:

«A/ La Exposición de Motivos de la Ley 4/99, cuando indica que «el silencio administrativo positivo producirá un verdadero acto administrativo eficaz que la Administración Pública sólo podrá revisar de acuerdo con los procedimientos de revisión establecidos por la Ley».

B/ Los principios de seguridad jurídica (art. 9.3 de la CE) y confianza legítima (art. 3.1 de la Ley 30/92), en virtud de los cuales la Administración no puede invocar extemporáneamente el hecho de que el silencio sea contrario a la Ley cuando lo ha podido hacer con anterioridad, ni con lesión de las legítimas expectativas de los particulares que han actuado confiados en que si la Administración no ha puesto obstáculos es porque lo pretendido es conforme con el ordenamiento jurídico.

C/ El criterio lógico interpretativo, que implica atender al espíritu y finalidad de la norma (art. 3.1 del CC [ LEG 1889, 27] ), de modo que la Administración no puede gozar de la potestad de desconocer los efectos del silencio positivo cuando no resuelva y sin embargo cuando resuelve expresamente - deber ineludible - quede vinculado por los efectos del silencio.

D/ Los debates parlamentarios, reveladores de la voluntad del legislador, por cierto bastante consensuada, de poner límites a las potestades administrativas respecto del silencio positivo (sesiones de 17.12.1998 y 8 de octubre de 1998, en la que se indica que la supresión de la certificación del acto presunto como obligatoria responde a la idea de que no se puede utilizar como mecanismo para revisar un acto favorable por silencio). Y en este sentido debe recordarse el dictamen del Consejo de Estado de 22 de enero de 1998 al Anteproyecto de Ley que sigue la línea expuesta.

E/ El espíritu de la reforma de la Ley 4/99, interpretada ésta de forma sistemática, que ha convertido a la obligación de resolver de la Administración en una obligación sujeta a un plazo esencial, de modo que ya no puede invocarse la doctrina general del art. 63.3 de la Ley 30/92 y su antecedente, la LPA de 17.7.1958 ( RCL 1958, 1258, 1469, 1504; RCL $1959,585)$, en el sentido de que «la realización de actuaciones administrativas fuera del tiempo establecido para ellas sólo implicará la anulabilidad cuando así lo imponga la naturaleza del término o plazo», por lo que tal precepto no será de aplicación cuando dichas actuaciones se refieran a la resolución, so pena de constituir una antinomia con el art. 42.1. A ello habría que añadir la desaparición del procedimiento de revisión de oficio de los actos anulables del viejo art. 103, de modo que cuando la solici- 
tud de una licencia urbanística suponga una infracción del ordenamiento jurídico (art. 63 Ley 30/92) la Administración habrá de acudir a la declaración de lesividad, lo que es indicativo que la mera infracción del ordenamiento jurídico no constitutiva de nulidad de pleno derecho no puede ser desconocida por la Administración.

F/ El criterio de la doctrina científica mayoritaria que ha tratado esta cuestión. En virtud de lo expuesto esta Sala revisa su doctrina estableciendo la que a continuación se expone: Transcurrido el plazo para resolver una solicitud de licencia, cuando el efecto del silencio sea positivo, la Administración competente, en caso de que no haya resuelto expresamente no podrá invocar que la concesión de la licencia por silencio es contraria al ordenamiento jurídico sino acudiendo a los procedimientos de revisión establecidos en el art. 102 y ss. de la Ley 30/92. Sin perjuicio de lo expuesto, la Sala no obstante, considera, con arreglo al art. 62.1.f de la Ley 30/ 92 de 26 de noviembre -evitando dar cobertura a actos jurídicos incursos en vicio de nulidad por inexistencia- y, con arreglo al art. $154.5^{\circ}$ de la LS de la CAM de 17.7.2001 ( RCL 2001, 2508 y LCM 2001, 385) cuando se refiere a que «se entenderá otorgada por silencio positivo en los términos resultantes del proyecto de obras de edificación», que para que tenga validez la doctrina anteriormente expuesta es preciso que la solicitud de una licencia urbanística cumpla estos requisitos: A/ Cuente con la documentación legal o reglamentariamente exigida, no bastando, v. gr. un acto comunicado para obtener una licencia de obra mayor sujeta a la presentación de un proyecto. Y ello en tanto en cuanto nos encontraríamos, de lo contrario, con un acto inexistente por falta de los requisitos esenciales. B/ Que dicha solicitud haya sido formulada, cuando se exija proyecto, por el técnico competente $(\ldots) »$.

En una línea argumental muy semejante, la STSJ de la Comunidad Valenciana de 3 de junio de 2005 (JUR 2005/211811) señala que una resolución administrativa tardía que vaya contra el silencio administrativo positivo, en teoría, no puede darse, pues una vez producido el silencio administrativo positivo se entiende que el procedimiento administrativo ha finalizado, según el artículo 43.3 de la Ley 30/1992.

Realizada esta afirmación de que el procedimiento de otorgamiento de licencia ha finalizado una vez producido el silencio administrativo positivo, se pregunta el órgano jurisdiccional qué efectos jurídicos debemos dar a la Disposición Adicional Cuarta de la Ley de las Cortes Valencianas 6/1994, de 15 de noviembre, reguladora de la Actividad Urbanística, según el cual en ningún caso se entenderán adquiridas por silencio administrativo licencias en contra de la legislación o del planeamiento urbanístico ${ }^{3}$.

\footnotetext{
3 Se trata de un precepto de gran raigambre en nuestra legislación urbanística, que aparece prácticamente en todas las legislaciones urbanísticas autonómicas, y que tiene su origen y el mismo tenor literal que el art. 242.6 TRLS92 (que a su vez tiene como antecedente el art. 178.3 TRLS76), cuya consti-
} 
Pues bien, entiende el TSJ de la Comunidad Valenciana en su fallo de 3 de junio de 2005 que dicho precepto debe ser interpretado según la modificación introducida en la Ley 30/1992 por la Ley 4/1999, en el sentido de que si un particular cuenta con una licencia obtenida por «silencio administrativo positivo», «la Administración no puede desconocer ni resolver en contra dentro del concreto procedimiento al haber éste finalizado, y, caso de entender que es perjudicial para el interés público, no le queda otra opción que acudir a los procedimientos de revisión de oficio y adoptar como medida cautelar la suspensión de la licencia obtenida por silencio administrativo positivo». El sentido de este precepto es, por tanto, «dar un mandato a la Administración para que, caso de haberse obtenido licencia por silencio administrativo positivo, impida la obtención de facultades que la Ley o los instrumentos de planeamiento no le conceden, y en modo alguno, el precepto supone una derogación de los procedimientos de la Ley 30/1992 modificada por Ley 4/1999». Por ello, en el supuesto de autos, se estima el recurso en el sentido de anular la denegación de la licencia de forma expresa, por cuanto el interesado habría adquirido la licencia por silencio administrativo positivo, debiendo la Administración demandada iniciar el procedimiento legalmente establecido de revisión de los actos administrativos si entiende que esa licencia vulnera el ordenamiento jurídico. Esta situación, como puede observarse, en nada difiere a la posición que debe adoptar la Administración cuando otorga una licencia de forma errónea.

También señala el TSJ de la Comunidad Valenciana en esta misma resolución judicial que venimos comentando que esta interpretación que ha realizado la Sala no es novedosa y que puede encontrarse en la legislación urbanística de otras Comunidades Autónomas: así, pone por ejemplo la Ley Catalana 2/2002, de 14 de marzo, de Urbanismo, en la que, aunque inicialmente el artículo 5.2 afirma «(...) En ningún caso pueden considerarse adquiridas por silencio administrativo facultades urbanísticas que contravengan esta Ley o el planeamiento urbanístico...», el artículo 180.2 -cuando pretende materializar la imposibilidad de adquirir facultades por silencio administrativo- es muy claro al señalar «(...) La competencia y el procedimiento para otorgar y denegar las licencias urbanísticas se ajustan a lo establecido en la legislación de régimen local. El sentido positivo del silencio administrativo en la materia se entiende sin perjuicio de lo dispuesto en el art. 5.2 y en el marco de lo establecido en la legislación aplicable sobre procedimiento administrativo común...».

Exactamente igual que el TSJ de la Comunidad Valenciana se expresa el TSJ de Navarra en su sentencia de 1 de septiembre de 2004 (JUR 20041305731): «Tal acto tiene todos los efectos que son propios del mismo

tucionalidad fue salvada, como consecuencia de su carácter básico, por la STC 61/1997, de 20 de marzo (FJ 34) en el entendimiento de que constituía ejercicio de la competencia estatal en materia de bases del régimen jurídico de las Administraciones públicas y del procedimiento administrativo común ex art. 149.1.18 ${ }^{\text {a }}$ CE, y cuyo vigor se ha mantenido con la Ley 6/1998, de 13 de abril, de Régimen del Suelo y Valoraciones. 
como si se tratase de un acto expreso; al respecto es claro el contenido del artículo 43.3 de la Ley 30/92, de 26 de noviembre, cuando expresa que «la estimación por silencio administrativo tiene a todos los efectos la consideración de acto administrativo finalizador del procedimiento». Tal acto por consiguiente ha de entenderse como válido y producir los efectos que le son propios, siendo solo atacable por las vías de revisión de oficio o impugnación previa declaración de lesividad previstas en los artículos 102 y siguientes de la dicha Ley 30/1992, siendo del todo punto irrelevante la resolución tardíamente notificada una vez que se ha producido el juego del silencio administrativo positivo».

\section{RÉGIMEN JURÍDICO DEL SILENCIO POSITIVO EN CASOS DE POSIBLES DEFICIENCIAS EN LA SOLICITUD DE LA LICENCIA}

La legislación urbanística exige que la solicitud vaya acompañada de proyecto técnico, pues tal documentación permite a la Administración, en el ejercicio del control de la autoridad que encierra la concesión de licencia, evaluar las características intrínsecas y extrínsecas de lo solicitado para bien, como acto reglado que es, acceder a su concesión o, en su caso, informar al peticionario de los aspectos que debe corregir para respetar la legalidad vigente.

Conforme al artículo 9.1.4 $4^{\circ}$ del Reglamento de Servicios de la Corporaciones Locales y a la Ley 30/1992, en el caso de que se observen deficiencias subsanables en la solicitud de una licencia se notificará o requerirá al solicitante de la misma antes de expirar el plazo para resolver, a los efectos de que sean subsanadas tales deficiencias, suspendiéndose el plazo máximo para resolver desde la notificación del requerimiento hasta su cumplimiento por el interesado, o, en su defecto, hasta el transcurso del plazo concedido para la subsanación. De acuerdo con una acusada línea jurisprudencial (por todas, STS de 20 de julio de 1990, RJ 199016581), dado que el silencio positivo tiene como finalidad amparar al ciudadano frente a la inactividad administrativa, el cómputo de los plazos necesarios para resolver acerca de una licencia -art. 9.1.7. ${ }^{\circ}$ del Reglamento de Servicios de las Corporaciones Locales- ha de llevarse a cabo teniendo en cuenta que el plazo de subsanación de deficiencias es una «prórroga» —ésta es la terminología del precepto indicado- de suerte que producida la notificación de las deficiencias subsanables, deja de correr el plazo y llevada a cabo la subsanación vuelve a correr aquél, teniendo en cuenta el lapso temporal anterior a dicha notificación, hasta completar el plazo necesario: éste se obtiene, pues, sumando los tiempos anteriores a la notificación de las deficiencias subsanables y posterior a la subsanación.

No se llega a regular en la legislación citada qué ocurre cuando se requiere al solicitante de la licencia para que proceda a subsanar deficiencias una vez transcurrido el plazo para resolver acerca del otorgamiento de la licencia. 
La jurisprudencia ha tenido ocasión de pronunciarse sobre esta cuestión. Así, entiende el TSJ de La Rioja, ante un supuesto en el que el solicitante de la licencia no cumplió los requisitos formales de solicitud (por ausencia de proyecto técnico) y la Administración no le requirió en su momento para que aportase dicha documentación, sino tres años después de solicitada la licencia, que la licencia se entiende concedida por silencio positivo, pues de lo contrario se vulnerarían los principios de confianza legítima y buena fe. Concretamente, afirma el TSJ que la Administración «ha vulnerado el principio de buena fe y confianza legítima que debe presidir las relaciones jurídico-públicas (ex Ley 30/1992, de 26 de octubre, del Régimen Jurídico de las Administraciones Públicas y Procedimiento Administrativo Común, en delante LRJPAC, artículo 3), de importancia radical; no en vano, el Tribunal Supremo se ha referido a él como un principio «tan necesitado de ser observado en las relaciones jurídicas, y, claro está, en las relaciones jurídico-administrativas» (sentencia de 11 de mayo de 1978), necesario para una normal convivencia en nuestra sociedad (sentencia de 18 de junio de 1979), relacionándolo con el principio de seguridad jurídica (sentencia de 27 de junio de 1984), insistiendo, en que la buena fe debe presidir, decíamos, toda relación entre Administración y administrados (sentencias de 23 de enero de 1976, de 3 de junio de 1981, 4 de julio de 1983, 25 de abril de 1984 y 21 de noviembre de 1986) y, por último, anteponiendo su presunción mientras no se pruebe lo contrario (sentencia de 4 de junio de 1992)». (STSJ de La Rioja de 18 de enero de 2001, JUR 2001\99400).

En sentido semejante resuelve la STSJ de la Comunidad Valenciana de 22 de mayo de 2001 (JUR 2001\303489), al afirmar que «no pueden dejarse pasar más de cinco meses en requerir una documentación; para ello está en la Ley el art. 71 de la Ley 30/1992 o el art. 9 del Reglamento de Servicios de las Corporaciones Locales de 1953 que establece con claridad unos plazos cortos para hacer el requerimiento con apercibimiento de archivo de las actuaciones». En consecuencia, se estima el recurso y se establece que el demandante obtuvo la licencia solicitada por «silencio administrativo positivo» y que si el Ayuntamiento estima que esta situación es lesiva para sus intereses para eso está el proceso de lesividad.

\section{E. DETERMINACIÓN DE LA FECHA DE SOLICITUD DE LA LICENCIA A EFECTOS DEL INICIO DEL PLAZO DEL SILENCIO POSITIVO. LA AUTOLIQUIDACIÓN PROVISIONAL DE TASAS POR LA LICENCIA}

El inicio del cómputo del plazo para resolver sobre el otorgamiento de la licencia puede dar lugar a errores como consecuencia de los requerimientos de subsanación de deficiencias, especialmente cuando se trate de aportar documentación obligatoria que no fue presentada en el momento de la solicitud, como 
pueda ser el proyecto técnico. En estos casos, indica la jurisprudencia no se puede tomar como dies a quo la fecha de aportación de la documentación exigida, sino la fecha de la solicitud de la licencia, ya que la falta de proyecto técnico determina para el Ayuntamiento, no la facultad de denegar la licencia, sino la de notificar al peticionario la existencia de defectos subsanables para que pueda subsanarlos en el plazo de 15 días, conforme a lo prevenido en el art. 9.1.4. ${ }^{\circ}$ del citado Reglamento (puede verse, por todas, STS de 10 de marzo de 1992, RJ 1992\3256, remitiéndose a las SSTS de 25 de mayo de 1982, RJ 1982\4133, y 15 de diciembre de 1986, RJ 1987\1050, SSTS de 3 abril, 17 marzo y 18 julio de 1986 - RJ 1986\1827 y RJ 1986\5130- y SSTS de 15 y 24 febrero, 14 marzo, 17 mayo, 28 julio y 7 octubre de 1988 —RJ 1988\1148, RJ 1988\1398, RJ 1988\2165, RJ 1988\3794, RJ 1988\6545 y RJ 1988\7447—).

También se pueden producir errores por el hecho de que compute como dies a quo no el de la presentación de la solicitud de licencia en el Registro del Ayuntamiento, sino el de abono de la tasa por la licencia urbanística. Sin embargo, el artículo 9.1.1 ${ }^{\circ}$ del RSCL y en general la legislación urbanística autonómica exigen que a la solicitud de licencia se acompañe proyecto técnico redactado por técnico competente, no haciéndose referencia en ningún caso al abono de las tasas por la licencia, por lo que no puede entenderse éste como un requisito para determinar el momento de solicitud de la licencia. En este sentido se pronuncia el TSJ de la Comunidad Valenciana, que revoca una sentencia apelada entendiendo que se ha interpretado de manera desacertada la fecha de la solicitud al referirla a la fecha de aportación al expediente del resguardo de la tasa por prestación de los servicios relativos a las actuaciones urbanísticas. «el procedimiento para la concesión de licencias sólo se entenderá iniciado cuando la petición vaya acompañada de proyecto técnico y de los demás elementos indispensables para dotar de contenido a la resolución. Y el caso es que, a la vista del expediente administrativo, ni se ponía de manifiesto por parte de la Administración ninguna carencia de elemento indispensable en la presentación de la solicitud (el resguardo de las tasas no lo es, al tratarse de un mero justificante formal de los efectos estimatorios o desestimatorios producidos por el transcurso del plazo para resolver expresamente -cfr. STS de 18 de julio de 2001, Ar. 2001/6186, dictada por la parte apelante-) ni ningún otro elemento relevante en el proyecto técnico formulado» (STSJ de la Comunidad Valenciana de 3 de junio de 2005 (JUR 2005\211811).

\section{F. RÉGIMEN JURÍDICO DEL SILENCIO POSITIVO EN CASOS DE EMISIÓN DE INFORMES PRECEPTIVOS EN EL MARCO DEL PROCEDIMIENTO DE OTORGAMIENTO DE UNA LICENCIA}

El artículo $9.12^{\circ}$ y $3^{\circ}$ del RSCL afirma que en el caso de ser necesario informe de algún Organismo, deberá remitírsele la documentación técnica a 
dicho Organismo para que proceda a la evacuación del informe en el plazo de cinco días tras la fecha de registro, de modo que, transcurrido el plazo para resolver la solicitud de la licencia (tres meses) sin haberse remitido el informe a la Corporación, deberá entenderse informada favorablemente la solicitud. Y el artículo 42.5 de la Ley 30/1992 ha venido a matizar aún más este régimen de la solicitud de los informes, en el sentido de que para que pueda suspenderse el cómputo de los plazos para resolver ha de tratarse de informes que sean preceptivos y determinantes del contenido de la resolución, que deberá notificarse tanto la petición de informe como la recepción del informe a los interesados y que se suspenderá el cómputo del plazo por el tiempo que medie entre la petición y la recepción del informe, no pudiendo exceder este plazo de suspensión en ningún caso de tres meses.

En este sentido, con apoyo en el artículo 9 del RSCL, ha declarado reiteradamente la jurisprudencia que la extemporaneidad del informe hace que éste resulte inútil: si transcurre el plazo para la emisión del informe sin que éste se haya emitido, se entiende que se produce la «presunción favorable de informe (...), sin limitación de ninguna clase y sin posibilidad de contradecir ya la situación creada por el descuido de la citada Administración Corporativa» (por todas, STS de 22 de marzo de 1991, RJ 1991\2248).

Por lo que respecta al incumplimiento de los requisitos formales de notificación de solicitud o recepción de informe a los interesados, afirma la jurisprudencia que no puede entenderse que la suspensión sea automática por el mero hecho de la solicitud del informe, y ello por los motivos siguientes: «En primer lugar, no con la solicitud del informe cabe ampliar el plazo de resolución, sino sólo con la de los «preceptivos y determinantes», de manera que, aunque se tratase de una «potestad» habría que ejercerla verificando, en primer lugar, que se trata de un informe de tal tipo y emitiendo un juicio al respecto. En segundo lugar, la Ley 30/1992, inspirada en principios de seguridad jurídica, pretende que los interesados conozcan cuál es el plazo máximo de resolución del expediente (véase por ejemplo el artículo 42.4) y choca con esta intención legal evidente el hecho de que pueda considerarse suspendido el plazo de resolución sin que el interesado lo sepa claramente (en el caso de autos ni siquiera se sabía que se había pedido el informe, como veremos, pues se conoce una vez que ya han transcurrido los tres meses de notificación de la resolución). Recientemente hemos declarado ya en la sentencia 139 de 3 de marzo de 2004 ( JUR 2004, 96740), en interpretación del artículo 17.4 del RD 1398/1993, de 4 de agosto ( RCL 1993, 2402), que regula un caso parecido al del artículo 42 de la Ley 30/1992 ( RCL 1992, 2512, 2775 y RCL 1993, 246), que cuando la norma establece que se podrá suspender el plazo, desde luego es preciso que así se haga para que el efecto se produzca, cosa lógica dado que la caducidad es una institución directamente ligada a la seguridad jurídica que reclama que si se suspende el plazo de resolución se conozca tal hecho por quién está implicado en el expediente en el que se produce la suspensión» (STSJ de Castilla-La Mancha de 4 de oc- 
tubre de 2004, JUR 2004\292157; igualmente, aunque en el marco de un procedimiento sancionador, lo reconoce así la STSJ de Galicia de 13 de julio de 2005, JUR 2006\4795; STSJ de Canarias — Santa Cruz de TenerifeJUR 2003।243604, en el ejercicio de actividades turísticas).

\section{G. CONCLUSIONES}

Aunque la licencia solicitada pueda entenderse concedida por silencio positivo a favor del particular interesado, este hecho no excusa a la Administración de su deber de responder. Esta respuesta, como ya nos consta, no puede ser otra que la de confirmar la existencia del acto de licencia en el sentido solicitado por el particular. Si el Ayuntamiento considerase que el acto concedido es ilegal tendría que ejercitar su potestad de revisión de oficio de la licencia otorgada.

El momento que pone inicio al cómputo del plazo de tres meses de silencio es el de la solicitud de la licencia. Salvo casos en que no es posible siquiera entender que la licencia se ha presentado en debida forma, la regla general es que, si la Administración entiende que es necesaria la emisión de informes de otras Administraciones por ser preceptivos, o si entiende que la solicitud es incompleta o defectuosa, ha de notificarlo al particular afectado y ha de decretar la suspensión del procedimiento requiriendo (en el segundo caso referido) la subsanación de los defectos solicitando la documentación que estime pertinente. O también puede denegar la licencia concedida. Lo que no cabe, siguiendo la mejor doctrina jurisprudencial expuesta supra, es desconocer este tipo de requisitos necesarios, desconsiderando la existencia de un silencio positivo cuyo significado es el otorgamiento de la licencia.

Por otra parte, nos consta que no cabe equiparar el momento de la autoliquidación provisional de tasas por la licencia de obras con el momento de la solicitud de la licencia, aunque tampoco necesariamente con el de su otorgamiento. Lo más relevante parece ser estar a los criterios generales jurisprudenciales y legales expuestos, en el sentido de entender que sólo cabe considerar válidamente interrumpido el plazo de silencio positivo cuando la Administración suspende formalmente el procedimiento y lo notifica al particular. Ante este caso, el plazo no transcurriría mientras estuviera el procedimiento suspendido por causa de la petición de informes preceptivos sectoriales o por causa de la necesaria subsanación de la documentación de la licencia. 